\title{
Transtorno de estresse pós-traumático de início tardio? Reflexões diagnósticas baseadas em um relato de caso
}

\author{
Delayed-onset post-traumatic stress disorder? \\ Diagnostic reflections on a case report \\ Márcia Freitas', Zanon Passos', Leonardo F. Fontenelle, ${ }^{1,2}$
}

\section{RESUMO}

Objetivo: Neste estudo, o objetivo foi relatar o caso de uma paciente com transtorno de estresse pós-traumático (TEPT) de início aparentemente tardio e os diferentes dilemas surgidos durante seu diagnóstico. Método: Relato de caso. Resultados: Paciente feminina, de 34 anos, casada e do lar, apresentou TEPT 25 anos após o desabamento de sua residência durante uma enchente. O quadro surgiu após relatos na imprensa de eventos semelhantes associados ao soterramento de dezenas de vítimas em um município vizinho. Conclusão: Este caso sugere que pacientes podem desenvolver quadros semelhantes ao TEPT de início tardio após a reexposição a eventos previamente desprovidos de impacto emocional.

\section{Palavras-chave}

Transtorno de estresse póstraumático, psicopatologia, aspectos clínicos.

\section{Keywords}

Post-traumatic stress disorder, psychopathology, clinical aspects.

\section{ABSTRACT}

Objective: In this study, our objective was to report a patient with an apparent diagnosis of delayed-onset posttraumatic stress disorder (PTSD) and the different dilemmas faced during the diagnostic process. Method: Case report. Results: A female patient, aged 34, married, housewife, presented PTSD 25 years after the collapse of her home during a flooding. The condition emerged after press reports of similar events associated with the death of dozens of victims in a nearby town. Conclusion: Our case suggests that patients may develop conditions that bear resemblance to late-onset PTSD after re-exposure to events previously devoid of emotional impact.

\section{INTRODUÇÃO}

O subtipo de transtorno do estresse pós-traumático (TEPT) de início tardio, cujos sintomas se instalam pelo menos seis meses após o evento traumático, foi descrito formalmente em 1980 1,2. Uma revisão sistemática apontou para uma prevalência extremamente variável dessa condição, que acometeria de 0\% até $68 \%$ dos pacientes com TEPT em geral'. Essa grande variação foi atribuída a diferenças no tipo de trauma, nas definições de
TEPT de início tardio, nos desenhos dos estudos, nos métodos de avaliação e nas durações dos períodos de follow-up. Casos de TEPT de início tardio que ocorrem em populações civis, não precedidos por quaisquer sintomas de TEPT ou que se instalam mais de 12 meses após o evento traumático, foram descritos como muito raros ${ }^{1}$. Neste estudo, nosso objetivo foi relatar o caso de uma paciente com diagnóstico de TEPT de início aparentemente tardio (ou pseudotardio) e os diferentes dilemas surgidos durante o processo diagnóstico dessa condição.

1 Universidade Federal Fluminense (UFF), Instituto de Saúde da Comunidade, Departamento de Psiquiatria e Saúde Mental, Niterói, RJ.

2 Universidade Federal do Rio de Janeiro (UFRJ), Instituto de Psiquiatria, Programa de Ansiedade e Depressão, Rio de Janeiro, RJ. 


\section{RELATO DE CASO}

Sra. A., dona de casa de 34 anos, casada, residente do município de São Gonçalo, RJ, com ensino fundamental incompleto, iniciou o acompanhamento ambulatorial em virtude de sintomas depressivos que se iniciaram dois anos antes. Descrevia tristeza e perda do prazer nas atividades diárias na maior parte do tempo e em quase todos os dias, dificuldade de concentração, sentimento de menos-valia e de culpa, inquietação, redução do apetite com perda de peso e insônia inicial. Não havia relato de episódios semelhantes no passado.

Durante o exame do estado mental, a Sra. A relatou também um intenso "medo de chuva", que a fazia "perder o controle". Esses sintomas teriam aparecido há um ano, após uma tempestade acompanhada do desabamento de diversas casas e morte de dezenas de pessoas no município vizinho de Niterói, no estado do Rio de Janeiro. Embora sua casa não tenha apresentado quaisquer avarias, a Sra. A alega ter acompanhado o evento pela imprensa, o que a teria deixado atordoada, com extrema angústia e pavor.

Desde então, a Sra. A. passou a ter pesadelos recorrentes, cujos conteúdos envolviam desabamentos, mas que não incluíam lembranças específicas de um evento traumático realmente ocorrido. Ao presenciar tempo chuvoso ou nebuloso, a Sra. A passou a evitar ao máximo sair de casa, jogando-se debaixo da cama, sentindo suas mãos geladas e apresentando tremores em membros superiores. Os filhos, ao notarem essa atitude, ficavam aterrorizados. Depois do evento, afastou-se das pessoas, passou a acreditar que não tinha futuro e começou a sentir-se melhor só.

A Sra. A descreve que, aos 8 anos de idade, a casa onde morava desabou após uma forte tempestade. Na ocasião, não houve vítimas, mas sua casa ficou totalmente destruída. Embora tenha se assustado com o ocorrido, esqueceu-se do evento com o tempo. Quando chovia, sentia um leve desconforto, mas não evitava sair de casa ou deixava de executar suas tarefas habituais.

A Sra. A nasceu de parto normal a termo em ambiente hospitalar. Seu desenvolvimento psicomotor não se caracterizou por maiores alterações. Frequentou a escola sem apresentar dificuldades no aprendizado. No entanto, interrompeu os estudos ainda no ensino fundamental, pois o pai acreditava que mulheres não precisavam estudar. Caracteriza a família como "problemática e machista". Segundo a Sra. A, sua mãe sempre foi "seca" e pouco atenciosa. Há três anos passou a ser cuidadora de sua ex-cunhada, que é portadora de mielite transversa, atividade que segue realizando.

Seu pai e sua mãe são etilistas. Tem 11 irmãos, um dos quais também é etilista e os outros 10 são saudáveis. A Sra. A tem dois filhos, frutos de diferentes relacionamentos: um menino de 14 anos, com paralisia cerebral, e uma menina de 10 anos, saudável. Reside em casa de alvenaria com seis cômodos, onde moram cinco pessoas, incluindo companhei- ro, filhos e cunhada. Fazia uso esporádico, mas em grande quantidade, de derivados etílicos e cigarro desde os 9 anos, mas interrompeu o uso há 14 anos.

\section{DISCUSSÃO}

Neste relato, descrevemos uma paciente que apresentou TEPT de início "pseudotardio", com intervalo de 25 anos entre a exposição do evento supostamente traumático e a instalação completa da síndrome. O interesse na descrição deste caso é ilustrado pela controvérsia em torno da validade desse subtipo de TEPT, que tem sido encarado com ceticismo por diferentes pesquisadores. Alguns autores sugerem, por exemplo, que o TEPT de início tardio resulta de um exame do estado mental superficial, o que explicaria a prevalência elevada em estudos epidemiológicos e sua virtual ausência na prática clínica'. De fato, uma série de observações levanta dúvidas quanto ao enquadramento de nossa paciente no referido diagnóstico.

Em primeiro lugar, os sintomas intrusivos, fundamentais para o diagnóstico de TEPT, não incluíram memórias específicas do desabamento ocorrido na infância, mas apenas desabamentos em geral. De fato, a DSM-IV-TR não faz qualquer menção à possibilidade de que o conteúdo dos sintomas intrusivos seja referente ao conceito global do evento traumático (e.g., desabamento), e não ao evento traumático em si (e.g., desabamento da residência ocorrido durante a infância) $)^{2}$. Na ausência do sintoma intrusivo, o diagnóstico de TEPT não poderia ser realizado, cabendo, por exemplo, o diagnóstico de fobia específica do tipo ambiente natural. No entanto, como pesadelos não fazem parte dos critérios diagnósticos de fobia específica, acreditamos que o diagnóstico de TEPT seja mais apropriado.

Em segundo lugar, embora teoricamente traumatizante, o primeiro desabamento não foi descrito pela Sra. A como um evento propriamente aterrorizador. De fato, seu relato sobre o evento ocorrido em sua infância foi relativamente burocrático e, aparentemente, sem maior impacto emocional. No entanto, devemos lembrar que a DSM-IV-TR sugere que crianças expostas a eventos traumáticos podem não descrever os fenômenos que acompanham eventos traumáticos tipicamente observados em adultos, como medo, desamparo ou horror ${ }^{2}$. Além disso, evidências crescentes sugerem que experiências subjetivas negativas associadas aos eventos potencialmente traumáticos não são estritamente necessárias para o desenvolvimento de TEPT ${ }^{3}$.

Finalmente, embora a paciente tenha acompanhado desabamentos recentes apenas pela imprensa, e não pessoalmente, acreditamos que o segundo evento traumático foi o principal determinante do quadro de TEPT. No entanto, chama a atenção o fato de a paciente ter sido exposta previamente a um evento traumático de conteúdo idêntico (i.e., 
desabamento) e com graves implicações materiais e pessoais. Em um estudo de seguimento, Horesh et al. ${ }^{4}$ observaram que eventos estressantes mais recentes contribuíram de forma mais significativa para a variância na idade de início do TEPT, sugerindo que um TEPT "latente" pode ser precipitado por gatilhos ambientais. Dessa forma, o primeiro evento traumático pode ter sensibilizado nossa paciente aos efeitos de futuros traumas, especialmente aqueles envolvendo desabamentos ou desastres naturais.

Em resumo, nosso caso sugere que pacientes podem desenvolver quadros semelhantes ao TEPT de início tardio após a reexposição a eventos previamente desprovidos de impacto emocional. Acreditamos que o segundo desabamento, ainda que visto pela televisão, tenha sido o principal determinante do TEPT, o que torna o quadro típico, e não de início tardio. A elevada frequência com que eventos traumáticos ocorrem ao longo da vida podem resultar em artefatos relacionados à idade de início do TEPT. Inúmeras questões, incluindo a definição de trauma e de outros sintomas de TEPT na DSM-V, devem orientar as pesquisas futuras sobre TEPT de início tardio.

\section{REFERÊNCIAS}

1. Andrews B, Brewin CR, Philpott R, Stewart L. Delayed-onset posttraumatic stress disorder: a systematic review of the evidence. Am J Psychiatry. 2007;164(9):1319-26.

2. American Psychiatric Association. Diagnostic and Statistical Manual of Mental Disorders. 4a edition, text revision ed. Washington, D.C.: American Psychiatric Publishing; 2000.

3. O'Donnell ML, Creamer M, MCFarlane AC, Silove D, Bryant RA. Should A2 be a diagnostic requirement for posttraumatic stress disorder in DSM-V? Psychiatry Res. 2010;176(23):257-60.

4. Horesh D, Solomon Z, Zerach G, Ein-Dor T. Delayed-onset PTSD among war veterans: the role of life events throughout the life cycle. Soc Psychiatry Psychiatr Epidemiol. 2010. 